\title{
Antiprincesas e anti-heróis: a literatura infantojuvenil e a desconstrução de estereótipos de gênero.
}

Rosangela Fernandes Eleutério rosangelaeleuterio@gmail.com Universidade Federal de Santa Catarina, Universidade Federal
Florianópolis,., Brasil.

\author{
RESUMO
}

O presente trabalho tem como objetivo apresentar uma nova coleção da literatura infanto-juvenil intitulada "Coleção Antiprincesas e Anti-heróis". Apresentando personalidades históricas, exemplos de pessoas corajosas que foram além dos estereótipos feminino/masculino e criaram sua arte. Os livros incentivam jovens leitores a olhar o mundo sob novas perspectivas, saltar obstáculos e conhecer celebridades literárias e da música que deixaram obras que estão além do nosso tempo. Descontrói a ideologia de papéis de gênero, explicando para crianças que meninas não precisam ser frágeis e delicadas, tampouco os meninos fortes e "durões", reconhecendo que as culturas e sociedades são dinâmicas e mudam. As obras foram lançadas pela editora argentina Chirimbote em 2016. Inicialmente lançadas em espanhol, agora estão sendo traduzidas para o português e lançadas no Brasil pela distribuidora Sur. Com essa nova possibilidade de leitura entre crianças e jovens, pode-se fazer reflexões sobre gênero, cultura e sociedade. Como exemplo, neste trabalho será refletido particularmente sobre a literatura infantil de Clarice Lispector, que se tornou referência como uma das mais famosas "antiprincesas" do Brasil.
\end{abstract}

PALAVRAS-CHAVE: Literatura infantojuvenil. Desconstrução de gênero. Ideologias. Estereótipos. 


\section{INTRODUÇÃO}

A literatura infantil sempre foi julgada e avaliada com base no triângulo criança - família - escola. Constantemente a tendência era usar os livros com finalidade educacional. No entanto, o erro subjacente em literatura infantojuvenil é a concepção que ameaça relegá-la dentro dos limites da subliteratura e não explorar devidamente os seus conteúdos. Outro fator que problematiza a escrita feita para crianças, reside no fato de que o objeto da pesquisa, se torna frequentemente as crianças lendo dentro das escolas, como apenas mais uma obrigação escolar, sem relacionar literatura com a vida cotidiana (MASTANTUONO, 2016).

Os livros escolhidos para leitura obrigatória, tanto no ensino fundamental quanto no ensino médio, muitas vezes deixam a desejar quanto a discussão reflexiva de seus temas. Em vez de histórias inspiradoras que estimulem a criatividade e questionamentos do mundo, crianças e jovens estão lendo adaptações e reescritas de obras clássicas, com finalidade de ensina-las uma possível "lição de moral" ou noções de cultura geral. (MASTANTUONO, 2016), sem um propósito que provoque uma relação entre literatura, reflexão, educação e ética.

No Brasil, sob perspectiva histórica, as propostas metodológicas adotadas eram dirigidas à obra infanto-juvenil de Monteiro Lobato. "Contribuiu-se, nesse sentido, com a formação de pedagogos e professores de língua e literatura, oferecendo um panorama sobre a odisséia da produção lobatiana nas unidades de ensino, entre as vertentes educacionais e textuais que vigoram no século XX" (LUIZ, 2005, p. 22). As consagradas obras de Monteiro Lobato se tornaram clássicos infantis e leitura obrigatória entre as crianças e jovens. Ganhou adaptações para a tv e assim cada vez mais se popularizou e agradou ao público que não tinha muitas opções de obras de referência nas escolas. Monteiro Lobato como ícone literário infantil predomina até hoje, porém, atualmente, novos estudos começam a questionar a pertinência de suas temáticas dentro das histórias.

Entrar no mundo das histórias, diverte, ensina, estimula a linguagem, a imaginação e oferece à criança a possibilidade de vivenciar experiências prazerosas que as libertem da mediocridade cotidiana. É na relação lúdica com a obra literária que temos a possibilidade de formar um leitor. Os livros também podem ser um pretexto para ensinar a leitura, língua, a aquisição de novas palavras, a análise de discurso, a identificação dos diferentes gêneros literários, a vincular/diferenciar fantasia e realidade, entendimento do comportamento social e oportunidade de incentivá-las a inventar suas próprias histórias. Enfim, a leitura na infância oferece incontáveis benefícios que podem transformar a vida de uma pessoa e defini-la como indivíduo.

Isso remete a imensa responsabilidade da escolha do que se ler para uma criança. Tanto no âmbito escolar quanto no familiar, os livros devem conter informações que moldarão de forma positiva e edificante as mentes jovens de seus leitores. E nesse processo, a participação ativa do adulto é de extrema importância. Os educadores devem ter em mente o tipo de olhares e interpretações que determinados livros oferecem e analisar sua coerência com a 
idade do leitor, com a perspectiva de mundo que a história contida no livro apresenta e quais valores morais devem ser relevados.

Uma consideração importante feita pelo filósofo italiano Giorgio Agamben provém da relação que as crianças têm com as histórias imaginativas. Segundo o filósofo "é provável que a invencível tristeza que as vezes toma conta das crianças nasça da consciência de não serem capazes de magia" (AGAMBEN, 2007, p. 23). Com certo pessimismo, Agamben ainda sugere que aquilo que conseguimos por mérito próprio não é capaz de proporcionar a felicidade, que somente a magia é capaz de tal mérito $(2007$, p. 23). Será esse um dos motivos que as histórias de contos de fadas, de heróis e princesas, fazem tanto sucesso entre as crianças? Para um menino é muito importante ter força extraordinária, superpoderes e inteligência aguçada. Para as meninas, beleza infinita, vestidos lindos, um príncipe que as ame e lhes dê o valor de uma "joia rara". Mas quem estabeleceu a quem beleza e força devam ser relacionados? Não pode um menino ter beleza infinita e uma menina superpoderes?

A literatura infanto-juvenil atualmente vem reforçando estereótipos que devem ser vencidos, desconstruídos e assim libertando mentes de preconceitos reforçados ao longo das décadas. Questionar o conteúdo das obras de Monteiro Lobato é um importante passo para reflexão de uma nova era na educação, mas a introdução de livros que auxiliam debates e pontos de vista a partir de novos ângulos tem um papel cada vez mais inovador e necessário. Não que se deva apagar a magia dos livros de histórias, mas sim acrescentar os méritos próprios de seus personagens como um importante fator de possível felicidade. Por isso é importante refletir e discutir sobre a nova coleção de livros infantis lançados pela editora argentina Chirimbote, pois ela tem a ambição de ensinar às crianças a encontrarem as forças que já existem dentro delas e transforma-las em uma história de vida extraordinária e cheia de magia.

\section{A DESCONSTRUÇÃO DE GÊNERO COMO PRÁTICA INEVITÁVEL NA LITERATURA.}

Uma das questões levantadas nas escolas que causam mais conflitos de opiniões entre pais, professores, diretrizes escolares e até políticas é a pergunta: É possível falar sobre diversidade de gênero e/ou representações de gêneros com crianças pequenas? (PORTO, 2016, p. 01). Embora haja uma conduta do politicamente correto e o pudor de algumas escolas em não tratar sobre sexualidade, é importante ressaltar e não ficar indiferentes ao fato de que as perguntas e respostas estão no nosso cotidiano (PORTO, 2016, p. 01). As crianças possuem sensibilidade e inteligência para perceber que há uma diferença entre o que lhes é dito e o que veem nos meios sociais nos quais circulam. É importante que pais e professores estejam atentos a essa capacidade de compreensão e crítica que as crianças desenvolvem naturalmente na inteiração com o outro.

Um dos exemplos é a atual configuração de família. Não há como crianças criadas em famílias tradicionais ficarem indiferentes diante coleguinhas que tem dois pais ou duas mães, ou que são filhos de pais ou mães solteiros. Há as que são criadas pelos avós, as crianças que são adotadas e as de família inter-raciais, entre outra diversidade de configurações familiares. Enfim, isso precisa ser discutido, mostrado e refletido para que desconstrua antigos preconceitos que 
interferem na formação intelectual dos alunos. As crianças são parte da história, cultura, sociedade civil e política que não permitem exclui-las de discussões que interferem em suas liberdades de escolha e expressão (PORTO, 2016, p. 02). Precisam de um programa educacional que as possibilitem de formar opiniões próprias e lutar por si mesmas, contra as repressões que podem estar sofrendo por consequência de uma educação castradora e sufocante.

Não se deve negar a crianças e jovens o direito ao debate sobre as ideologias contemporâneas. Os livros infantis que deveriam ser grandes aliados na educação desses alunos estão separando o mundo entre princesas, príncipes e monstros. Mas quem são esses monstros? Aqueles que pensam diferente da maioria? A menina que gosta de jogar futebol ou o menino que prefere dançar balé? Separar, rotular e classificar pessoas é um ato perigoso que pode ser um dos piores males existentes na contemporaneidade e responsáveis por tantas doenças psicológicas que vêm surgindo como se fossem produtos de massa.

Paralelamente a educação rígida, antiquada e tradicional, vem surgindo na literatura brasileira livros que abordam temas até hoje tido como tabus. Por exemplo, os livros da coleção sobre antiprincesas e anti-heróis que trazem em cada um deles, temas relacionados às relações homo afetivas, como a bissexualidade de Frida Kahlo. Questões feministas como a vida livre de amarras das responsabilidades familiares de Violeta Parra. Questiona o que é crença e religião ao tratar o atributo de santa que Gilda recebeu de seu povo por ser capaz de realizar "milagres" e também o estrangeirismo de Clarice Lispector. Os chamados anti-heróis descontroem o ideal do homem forte e sem emoções para apresentar aos leitores a doçura e sensibilidade de escritores como Eduardo Galeano e Júlio Cortázar, cujas vidas foram dedicadas à escrita, poesia e contemplação dos mistérios do ser humano.

Tratar desses temas com crianças parece complicado, mas não por estar associado a capacidade cognitiva desses indivíduos, mas sim por questões relacionadas a linguagem. Tudo deve ser dito de maneira sutil, explicativa, desmistificada, porém fazer omissões cautelosas é um dado muito relevante. Afinal as personalidades reais escolhidas para compor a saga de celebridades a serem reconhecidas como exemplos de vida para os alunos, contém em suas biografias relatos de dor, traições, problemas éticos, saúde mental, entre outros assuntos que não seriam apropriados dizer em um livro infantil, afim de não tirar das crianças o encanto e a magia em que acreditam. A literatura infanto-juvenil tem responsabilidade social e os não-dizeres devem estar nas entrelinhas, para que, no momento oportuno das idades escolares, certas questões possam ser retomadas. Como afirma Sartre sobre literatura: "Pode-se encontrar, sem dúvida, na origem de toda vocação artística, uma certa escolha indiferenciada que as circunstâncias, a educação e o contato com o mundo só mais tarde irão particularizar" (2004, p. 09).

Isso na verdade não chega a ser um problema, pois a literatura existe precisamente para isso, entre outras coisas. Para trazer uma linguagem repleta de significados. Mas o que é linguagem falada ou escrita? Ezra Pound apresenta várias possibilidades de definições como "um conjunto de signos representando vários ruídos", (2006, p. 32) E fala também da linguagem em outra espécie como se fosse "um desenho do gato, ou de algo que se move ou existe, ou de um grupo de coisas que ocorre sob certas circunstâncias ou que participa de uma qualidade entre todas elas" (POUND, 2006, p. 33). A linguagem é a vida se movendo entre 
os pensamentos, em mentes que devem ser constantemente alimentadas com perguntas. Serpenteando uma infinidade de assuntos que buscará respostas que coloquem os velhos ditados e normas sob uma perspectiva de luz e novos entendimentos.

Uma das personalidades que compõe a coleção antiprincesas e que aqui será abordada com maior particularidade é Clarice Lispector. Entre todas, ela foi a "antiprincesa" que viveu a arte da escrita literária, escrevendo contos e romances de caráter filosófico e psicológico, que a torna uma autora sempre atual. Fez das palavras a sua arma de luta e resistência contra a sociedade, contra o que não considerava justiça. Foi a escritora mais famosa da literatura brasileira e ousou também, a pedido de seu filho Paulo, a escrever livros para crianças.

Suas obras são famosas por conter uma tensão psicológica que abala seus leitores e promove, no limiar da linguagem, reflexões acerca da existência humana, sobretudo da vida íntima do subconsciente feminino. Há em seus contos e romances, questões arraigadas a filosofia e ao feminismo que não passaram despercebidos em sua época e ainda são temas tão populares.

Mas o que uma escritora tão perturbadora tem a dizer em seus livros infantis? Para crianças ela escreveu: O mistério do coelho pensante (1967), A vida intima de Laura (1968), A mulher que matou os peixes (1974) e Quase de verdade (1978). Clarice Lispector não tinha a pretensão de publicar esses livros, porém os escreveram para compartilhar com seus filhos sua visão de mundo numa linguagem acessível, porém com toda arte e poética que lhe foram peculiares quanto escritora. Também traduziu diversos livros do gênero aventura imprimindo nessas traduções a sua marca.

\section{A VOZ NA LITERATURA INFANTO-JUVENIL QUE CONSAGROU CLARICE LISPECTOR COMO UMA DAS “ANTIPRINCESAS" BRASILEIRAS MAIS IMPORTANTES.}

Um dos livros infantis mais cativantes, e o primeiro que Clarice Lispector escreveu nesse gênero, é $O$ mistério do coelho pensante. Uma narração em primeira pessoa na qual a narradora se dirige a "Paulinho" (filho de Clarice) e fala sobre um coelho comum, porém que tinha muitas ideias. Mas que diferente das pessoas, esse coelho pensava com o nariz e quando o fazia, mexia e remexia tantas vezes as narinas até ficarem vermelhas. (LISPECTOR, 1999, p. 04) O coelho gostava de comer e fugir de sua gaiola. Fugia para ver a namorada, os filhinhos, os amigos, mas sempre voltava e ficava sozinho com seus pensamentos. Esse animalzinho era ousado, saía de sua intimidade e extrapolava os limites que foram delimitados para ele.

A narrativa poética é construída com subjetividade abrindo as portas à imaginação. "A narradora recorre a uma linguagem em que a prosa se alimenta constantemente da poesia, para dar espaço ou particularizar a história. Com a prosa, por outro lado, ela temporaliza a experiência, que se desdobra, complexado pela concomitância do passado, presente e futuro dentro da mesma história" (ALBERNAZ, 2010, p.03). O livro que foi escrito, ilustrado e publicado para o público infantil, tem um forte apelo filosófico que desafia não só a criança, mas também convida os leitores adultos a refletir sobre questões de liberdade e espaço. 
O simbolismo da gaiola, por exemplo, para qual o coelho sempre volta, pode representar a mente de um indivíduo. O coelho pensante precisa desse espaço para inventar formas de fugir. Escapar da própria mente para viver e ver o mundo ao seu redor é uma necessidade básica, mas sempre é necessário voltar para dentro de si mesmo. O livro é uma expressão de significados metafóricos que estimulam a imaginação e a linguagem. No final, ninguém consegue descobrir como o coelho consegue fugir, esse é o grande mistério. Porém Clarice Lispector não tenta resolve-lo. Deixa a mercê do leitor que busque alternativas para solucionar esse enigma e se tratando de um conto infantil, as possibilidades podem ser infinitas e surpreendentes.

Sob o olhar de Jean-paul Sartre sobre o que é literatura, $O$ mistério do Coelho pensante "se torna um objeto imaginário onde as coisas deixam de ser coisas e se tornam linguagem" (2004, p. 15), ou seja, cada elemento descrito no enredo tem um significado abstrato que pode mudar de formas. As escolhas de palavras feitas pela autora remetem a tendências profundas da escrita literária: "a escritora lida com significados" (SARTRE, 2004, p. 17) Esses significados são as razões para se escrever, para exteriorizar um pensamento que só através da literatura poderá ganhar uma performance itinerante e promover discussões. Ler e refletir em sala de aula um livro como de Clarice, permite dar voz aos alunos e estimula-los a expressarem ideias complexas e abstratas. Como o coelho sai da gaiola, a criança pode sair do seu campo imaginativo e atuar na língua com seu próprio objeto de construção, percepção e observação do texto.

Esse momento de exposição pode ser de extrema importância para que em público (sala de aula), as crianças possam compartilhar suas percepções do cotidiano e ajudar o educador em sua orientação sobre desconstruções de estereótipos do qual este trabalho vem tratando. Expressar-se deve ser uma escolha profunda, porém imediata que é comum a todos (SARTRE, 2004, p. 33). Faz parte da natureza do indivíduo deixar sua marca, imprimir seus pensamentos e contribuir com suas impressões de mundo. O problema é que nas escolas, apagando a literatura do currículo ou apenas ter livros como leitura obrigatória sem favorecer a discussão, faz com que todos os sentidos das obras sejam perdidos.

Ainda segundo Sartre, o espaço para a criação artística é uma necessidade para que seres humanos se sintam especiais num universo controverso e em constante transformação (2004, p. 35). E o objeto literário só pode existir em movimento, ou seja, o ato concreto da leitura (2004, p. 35). Os mesmos movimentos de reflexões existencialistas aparecem nos outros títulos escritos por Clarice Lispector para crianças. Cada um dos contos contém essa inclinação para a pós-história, para a continuação e livre interpretação de seus leitores. Em cada pensamento poético, Clarice Lispector imprimi uma sequência de suspense que levará jovens leitores a contribuírem para um determinado final.

\section{CONSIDERAÇÕES SOBRE O LIVRO CLARICE LISPECTOR PARA MENINAS E MENINOS}

O ano passado, a editora Chirimbote na Argentina, revolucionou a literatura infanto-juvenil com o lançamento de uma coleção que veio para derrubar estereótipos de gênero tão presente no cotidiano infantil. A escritora Nadia Fink 
ganhou o público com textos leves, palavras poéticas, inspiradoras e uma narrativa que encanta não somente as crianças, mas também adultos leitores. Outra coisa que cativa nos livros da coleção são as ilustrações feitas por Pitu Saá. Alternando entre fotos reais e desenhos divertidos, os livros são lúdicos, fáceis de ler e no final propõe atividades e reflexões sobre o/a personagem que intitula o livro.

Em Clarice Lispector, a sutileza da escritora Nadia Fink está em retratar não só aspectos da obra clariceana, mas falar com ênfase da infância de Clarice, de seu amor pelos animais, amor pelos filhos.... Mostra uma mulher tão humana e sensível com a qual qualquer criança pode se identificar. Nas ilustrações, Pitu Saá enfatiza uma das marcas físicas mais fortes e acentuadas da autora: Os olhos, as sobrancelhas arqueadas e também o rosto sério e expressivo. Desenha Clarice dessa forma até nas feições infantis e isso é uma característica que acrescenta muito charme ao livro, pois ensina também sobre imperfeições e particularidades físicas que nos tornam únicos. (FINK, 2016)

Para preparar os leitores, Nadia Fink prepara na página inicial uma apresentação breve e delicada. Convida os leitores infantis a uma experiência nova e interessante. Com as seguintes palavras, a escritora diz sobre Clarice Lispector:

Aqui vem uma nova Antiprincesa para continuar colocando as coisas de ponta cabeça como a gente tanto gosta. E quem melhor que Clarice Lispector, que virou pelo avesso as frases, os gêneros literários, retorceu as palavras e libertou os pensamentos. Esta brasileira se considerava uma "antiescritora" porque não gostava das estruturas, nem das coisas acadêmicas, nem das regras, porque escrevia onde e como podia: em papeizinhos, guardanapos ou com a máquina de escrever no colo, enquanto seus filhos corriam e ela atendia o telefone e os ajudava nos deveres de casa. Uma mulher trabalhadeira que teve vida de princesa na Europa e nos Estados Unidos e não gostou (ficou com náusea, entediada, sentiu-se um peixe fora d'água - ou uma peixinha), que voltou para sua terra querida e continuou trabalhando, e até escreveu livros para meninas e meninos como ela dizia, cujos protagonistas são uma galinha, um coelho pensante, ou um cachorro maluquinho que mastiga cigarros... A portinha do mundo de Lispector não é uma só, mas muitas e desiguais, e também janelinhas com pontos e vírgulas bagunçados para que nada esteja dito e tudo esteja por ser contado. (FINK, 2016)

Como é possível observar, desde a apresentação da obra Nadia Fink reflete sobre os lugares de cada coisa. "Clarice não gostava de estruturas, de regras", gostava de ser livre: "escrever em papeizinhos, guardanapos". A grande palavra implícita na apresentação é "Liberdade". O que o livro ensina é que o sujeito deve ser livre para ser quem é, sem medo das regras, ter ousadia para fazer aquilo que acredita ser o melhor para si. O conceito também é adotado em todos os livros da coleção e, nesse caso específico, desmistifica Clarice Lispector como escritora difícil. A autora é para ser lida e amada por seus leitores desde a mais tenra idade. Com essa apresentação pais e professores já tem material suficiente para debater em sala de aula ou discutir com os filhos os temas sugeridos. 0 desafio para os educadores é ter coragem. Item necessário para desconstruir 
seus próprios preconceitos antes de oferecer como uma ideia renovadora às crianças.

O conteúdo do livro traz além de frases famosas de Clarice Lispector, dados biográficos, elementos relacionados à infância da autora, palavras chaves que ajudarão as crianças leitoras em seu processo de desconstrução de estereótipos, conhecimento de história, valores, religião e cultura. Como por exemplo definições de: "Madame", “judaísmo", "Ucrânia", "realismo", "estranheza”, "crônica", "filósofos", "realidade social", "repressão", "ditadura". Todas palavras que fogem do contexto infantil, mas que no livro são expostas e explicadas ampliando assim a capacidade de entendimento linguísticos, culturais e históricos das crianças.

\section{A LITERATURA NA LUTA CONTRA O MACHISMO NA EDUCAÇÃO DE MENINOS}

A coleção não foca somente em mulheres. Os criadores das Antiprincesas também lançaram a série Anti-heróis, que fala sobre homens célebres. A ideia é contar a história de personagens importantes que fogem do estereótipo "hipermasculinizado", tão recorrente no imaginário das crianças. Oferece um contraponto para ser discutido com os leitores sobre machismo e feminismo, apontando exemplos reais da contemporaneidade literária. Essa conduta é totalmente pertinente devido aos conceitos de masculinidade que predomina nos valores culturais de nossa época. De acordo com Patrícia Alexandra Machado Correia:

Desde jovens somos educados com ideias do que significa ser homem e mulher, e a sexualidade e a orientação sexual têm um grande peso sobre essas ideias. Isto acontece, porque apesar de gênero e orientação sexual serem conceitos completamente independentes, a expressão de gênero tem influência em como a sociedade percebe ou assume as preferências de cada um. Também no sexo como ato, há expectativas daquilo que cabe a cada gênero. (CORREIA, 2015, p. 28)

A sexualidade dos meninos está sempre sendo a mais questionada e possui as mais conturbadas noções devido à formação e à grande preocupação, por parte dos pais, com a masculinidade de seus filhos (CORREIA, 2015, p. 28). Isso acontece como necessidade que os pais têm em reforçar a própria masculinidade nos seus filhos e porque as mães temem que suas crianças sejam ridicularizadas em seu grupo (CORREIA, 2015, p. 28). Assim criam uma situação de sufocamento emocional onde os indivíduos com suas mentes em formação se veem moldados para representações que muitas vezes estão longe da verdade íntima de cada pessoa. Reforçar a masculinidade dos meninos com livros de super-heróis, pode reforçar a ideia de que para ser "homem", não se deve dar espaço para evasões sentimentais.

A feminilidade, quando relacionada aos meninos, remete ao conceito de homossexualidade. Assim existe a crença, deturpada e estereotipada de que, brincar de boneca ou usar roupas rosas na infância pode tornar o menino necessariamente em um homossexual. Por isso a obsessão pelo ideal hipermasculinizados dos personagens literários infantis são reforçados em todos 
os meios educacionais e midiáticos. A importância da coleção anti-heróis é justamente romper com esse idealismo machista e mostrar que aos homens também é dado a arte, a música, a literatura, a dança, entre todas outras manifestações artísticas que requer sensibilidade e emoção para tornar real e vivo.

Desconstrução de estereótipos de gênero é necessária não apenas para libertar meninas da formação repressoras que as obriga a crescerem conscientes de que devem se casar, ter filhos e assumir responsabilidades domésticas. Ela é importante para libertar as meninas da ideia de que são seres frágeis e que precisam de um homem que as protejam. Desconstruir o idealismo de que são sexualmente vulneráveis, que devem ser bonitas e delicadas como bonecas, um objeto para deleite masculino é um dever imprescindível nos veículos literários.

As antiprincesas são aquelas que ousam ser livres para desafiar essas concepções opressoras, assim como os anti-heróis desafiam as concepções de que virilidade masculina, significa força e opressão sobre as mulheres. Forçar uma educação masculinizadora onde os meninos são ensinados que as mulheres são menos inteligentes e dependem da aceitação deles para serem valorizadas, envia a mensagem de que mulher é uma propriedade masculina. "E esta ligação intrínseca entre sexo e poder pode privar homens da possibilidade de vir a ter tipos diferentes de conexão íntima com outra pessoa" (CORREIA, 2015, p. 30).

Em relação ao termo machismo, se faz necessário explicar que a concepção não está relacionada somente aos homens, mas também as mulheres. A coleção antiprincesa sob o ponto de vista crítico da literatura infanto-juvenil é um grande avanço na luta contra a desconstrução de representação de papéis de gênero, mas também causou muita estranheza em pessoas, sobretudo mulheres, que acreditam, querem e sonham em serem princesas. 0 idealismo é tão arraigado que essa luta para desconstruir mentalidades ultrapassadas, ainda terá que ultrapassar muitas barreiras que compõe o comportamento social.

O machismo faz vítimas que na maioria das vezes são mulheres, mas não exclusivamente. A famosa e antiquada frase "menino não chora", ainda é muito popular e dita repetidamente aos meninos das diferentes classes sociais, em diversos contextos. O machismo tenta sufocar as lágrimas e as emoções dos meninos, que já crescem com duas ideias erradas: a de que eles não podem ter fragilidades e a de que toda menina é frágil por natureza. Os meninos também sofrem por serem privados de brinquedos e brincadeiras associadas às meninas. É possível que uma menina brincando de carrinho não cause a estranheza que um menino com uma boneca pode causar. O menino que ousar brincar de casinha tende a sofrer fortes reprimendas por parte de seus pais e se tornar motivo de riso entre seus pares.

Os anti-heróis não possuem as "virtudes" atribuídas aos heróis. Eles não são musculosos, nem fortes, nem esportistas. Eles não precisam possuir uma mulher como reforço de masculinidade. Não dependem das mulheres para lavar suas roupas e cozinhar sua comida. Não se sentem obrigados a deixar uma prole como sinal de sua potência sexual. Os anti-heróis são livres dessas amarras sociais tanto quanto as antiprincesas. Os personagens masculinos da coleção são homens distantes desses estereótipos citados acima. Ainda que questionados ou reprimidos, não se acanharam e como as mulheres, deixaram uma obra literária significativa e profunda que abre margem para o conhecimento de novos autores 
que também ultrapassaram as barreiras das concepções tradicionais do que é ser homem e ser mulher.

Eduardo Galeano, um dos anti-heróis retratados nos livros da coleção de Nadia Fink, foi um escritor uruguaio cujas obras se consagraram por denunciarem o sofrimento e a luta do povo latino-americano. Sua escrita é impiedosa e visceral em livros como As veias abertas da América Latina (1971) e a trilogia Memória do fogo (1982-1986). Porém em livros como O livro dos abraços (1991), Palavras andantes (1994) e Mulheres (1997), o autor usa uma linguagem profunda, filosófica e poética para repensar seu povo e sua cultura. Oferece aos leitores a oportunidade de entender os latino-americanos como um povo que deve muito a si mesmo e que deve ter orgulho de sua história de luta e coragem.

Julio Cortazar, outro anti-herói cuja biografia é tema de outro dos livros de Nadia Fink, foi um escritor argentino que optou pela nacionalidade francesa e sua escrita foi uma luta contra a ditadura e o regime militar na argentina. Foi considerado um dos autores mais originais e inovadores de seu tempo e escreveu muitas novelas, entre as mais famosas foi Rayuela (1963) e também contos, teatro e poesia. Foi um escritor com forte atividade política. Provocativo, causou algumas antipatias entre os intelectuais do seu tempo, porém nunca se deixou intimidar. Em comum, tanto Galeano quanto Cortázar não se limitaram as condições impostas por seu gênero e meio social. Assim como as mulheres, personalidades que compõe a coleção, utilizaram a força das palavras e expressões artísticas como ato de revolta e fidelidade a suas próprias identidades. Desafiadores e determinados não se limitaram a estereótipos e ideias pré-moldadas por uma sociedade castradora e antiquada.

\section{CONCLUSÃO}

O campo literário sobre desconstrução de gênero, ainda está no início, mas se torna cada dia mais promissor. O problema sobre o tema sexualidade e gêneros atualmente

têm sido amplamente abordados pelos instrumentos midiáticos, documentos oficiais, tanto para o âmbito escolar, quanto em programas de formação docente, no entanto, apesar da aparente abertura acerca da discussão da presente temática, muitos valores, preconceitos e tabus ainda são fortemente envolvidos no debate (DAROS, 2013, p. 174).

No processo do desenvolvimento sexual da criança, é perceptível que pais e educadores assumam o papel de repressores e controladores de seus comportamentos

dissimulando, escondendo, proibindo e omitindo as curiosidades naturais. Essas manifestações acabam sendo explicadas para as crianças de modo distorcido ou por meio de inverdades; e, mediante a ausência de respostas, alguns mitos podem ir se transfigurando em verdades (DAROS, 2013, p. 174). 
As famílias encontram muitos problemas em assumir a responsabilidade da educação sexual das crianças e por esse motivo, delegam aos professores a difícil tarefa. Por sua vez, de acordo com Daros, os professores muitas vezes também não estão preparados para abordar o tema de forma "apropriada, saudável e significativa" (2013, p. 174).

Frente a tanto desconforto gerado pelo tema, a sociedade se torna omissa. Há questões políticas a serem discutidas em relação à educação que envolvem as discussões sobre a abordagem de identidade de gênero nas escolas, porém ainda sofre resistências e controvérsias por parte dos pais: Muitos temem uma educação mais aberta, onde temas tabus podem ser discutidos abertamente. Por esse motivo, "trabalhar com conceitos, noções, construções e desconstruções que foram historicamente engendradas e legitimadas pela sociedade leva tempo, demanda estratégias e conhecimento científico" (DAROS, 2013, p. 175). Isso gera uma necessidade de trabalho em conjunto. Uma política onde pais e professores trabalhem juntos com um propósito em comum: Cultivar de modo saudável o pensamento crítico e a liberdade de expressão em nossas crianças. 


\title{
ANTIPRINCESSES AND ANTIHEROES: THE YOUNG-ADULT LITERATURE AND THE DECLINE OF GENDER STEREOTYPES
}

\begin{abstract}
This paper aims to present a new collection of children's literature books entitled "Antiprincesses and Antiheroes Collection" that features historical personalities, examples of brave people who went beyond feminine/masculine stereotypes and created their own art. The books encourage young readers to look at the world under new perspectives, jump over obstacles and meet literary and musical celebrities whose artistic works are beyond our time. These books disrupt the ideology of gender roles by explaining to children that girls do not have to be fragile and delicate, and that boys don't have to be strong and "tough" all the time, recognizing that cultures and societies are dynamic and change. The collection was launched by the Argentine publisher Chirimbote in 2016. Initially, they released it in Spanish, and now it's being translated into Portuguese and launched in Brazil by Sur. With this new possibility of reading among children and young people, they can make reflections regarding gender, culture and society. As an example, this work will discuss particularly the children's literature texts written by Clarice Lispector, who became a reference as one of the most famous anti-princesses of Brazil.
\end{abstract}

KEYWORDS: Young-adult literatura. Gender deconstruction. Ideology. Stereotipes. 


\section{REFERÊNCIAS}

AGAMBEN, Giorgio. Profanações. São Paulo: Boitempo, 2007. 95p.

ALbernAZ, Maria Beatriz. Poesia e Filosofia em "O Mistério do Coelho Pensante", de Clarice Lispector. 2010. Disponível em: <https://www.academia.edu/6080322/Poesia e filosofia em O mistério do c oelho pensante de Clarice Lispector?auto=download $>$. Acesso em: 23 jan. 2017.

CORREIA, Patrícia Alexandra Machado. 0 género na construção de personagens 3D: do binário ao fluído. 2015. Disponível em: <http://repositorium.sdum.uminho.pt/handle/1822/40794>. Acesso em: 24 jan. 2017.

DAROS, Thuinie Medeiros Vilela. Problematizando os Gêneros e as Sexualidades Através da Literatura Infantil. 2013. Disponível em: <http://www.ufjf.br/praticasdelinguagem/files/2014/01/172---186-

Problematizando-os-gêneros-e-a-sexualidade-através-da-literatura-infantil.pdf $>$. Acesso em: 23 jan. 2017.

FINK, Nadia. Clarice Lispector para meninas e meninos. Florianópolis: Chirimbote, 2016. 24 p. (Coleção Antiprincesas)

LISPECTOR, Clarice. O mistério do coelho pensante. Rio de Janeiro, 1999. 31 p.

LUIZ, Fernando Teixeira. A História do Ensino de Literatura Infantil no Brasil: Um Estudo sobre a Trajetória da Obra de Monteiro Lobato na Escola. 2005. Disponível em: 〈http://revista.fct.unesp.br/index.php/Nuances/article/view/1674/1591>.

Acesso em: 23 jan. 2017.

MASTANTUONO, Piera. La duplice identità della letteratura per l'infanzia. Disponível em: <https://www.atopon.it/la-duplice-identita-della-letteratura-perlinfanzia/>. Acesso em: 23 jan. 2017. 
Recebido: 24 jan. 2017

Aprovado: 13 mai. 2017

DOI: $10.3895 /$ rl.v19n24.5350

Como citar: ELEUTÉRIO, Rosangela Fernandes..Antiprincesas e anti-heróis: a literatura infanto-juvenil e a desconstrução de estereótipos de gênero. R. Letras, Curitiba, v. 19, n. 24, p. 1-14, marl. 2017. Disponível em: <https://periodicos.utfpr.edu.br/rl>. Acesso em: XXX.

Direito autoral: Este artigo está licenciado sob os termos da Licença Creative Commons-Atribuição 4.0 Internacional.

\section{(c) (1)}

